\title{
Cinsel İşlev Bozukluklarında Kanıta Dayalı Geleneksel ve Tamamlayıcı Tedavi Uygulamaları
}

\author{
Ceyda Su GÜNDÜZ ${ }^{1 *}$ iD, Özlem CAN GÜRKAN² \\ ${ }^{1}$ Marmara Üniversitesi, Sağlık Bilimleri Enstitüsü, \\ Doğum ve Kadın Hastalıkları Hemşireliği Anabilim Dalı, İstanbul, Türkiye \\ ${ }^{2}$ Marmara Üniversitesi, Sağlık Bilimleri Fakültesi, \\ Doğum ve Kadın Hastalıkları Hemşireliği Anabilim Dalı, İstanbul, Türkiye \\ *Sorumlu Yazar / Corresponding Author: Ceyda Su GÜNDÜZ, e-posta: ceyda_su_gndz@hotmail.com
}

\section{ÖZET}

Dünya Sağlık Örgütü cinsel sağlığı: "Sadece hastalık, işlev bozukluğu veya sakatlığın olmaması değil, fiziksel, duygusal, zihinsel ve sosyal yönden cinsellikle ilgili iyilik hali” olarak tanımlamaktadır. Bireylerin, çiftlerin ve ailelerin genel sağlı̆̆ ve refahında önemli bir yere sahip olan cinsel sağlığı etkileyen faktörler arasında cinsel işlev bozuklukları yer almaktadır. Dünyada ve Türkiye'de birçok birey cinsel işlev bozukluklarını yaşamaktadır. Erkeklerde erken boşalma, sertleşme bozukluğu; kadınlarda ise orgazm bozukluğu, cinsel ilgi/uyarılma bozukluğu gibi cinsel işlev bozuklukları bulunmaktadır. Cinsel işlev bozuklukları, çiftlerin ilişki kalitesini olumsuz etkilemekte hem kadın hem de erkekte anksiyete ve depresyona neden olabilmektedir. Günümüzde, cinsel işlev bozuklukları tedavisinde, medikal tedavinin yanı sıra geleneksel ve tamamlayıcı tedavi uygulamalarının kullanım sıklığı da tıp hekiminden veya batı tıbbından memnun olmama, tıbbi ilaçların yan etkilerinden kaçınma, doğal yöntemleri tercih etme gibi nedenlerden dolayı giderek artmaktadır. Ulusal Tamamlayıcı ve İntegratif Sağlık Merkezi bu yöntemleri doğal ürünler, zihin ve beden uygulamaları ve bu grupların hiçbirine tam olarak uymayan diğer tamamlayıcı sağlık yaklaşımları olarak ayırmıştır. Cinsel işlev bozukluklarının tedavisinde bu geleneksel ve tamamlayıcı tedavi uygulamalarından yararlanılmasına rağmen çok azının etkinliği kanıt düzeyi yüksek çalışmalarda gösterilmiştir. Bu derlemede kadın ve erkeklerde görülen cinsel işlev bozukluklarında yararlanılan geleneksel ve tamamlayıcı tedavi uygulamalarıyla ilgili yapılan çalışmaların kanıt düzeyleri incelenmiş̧ir.

Anahtar kelimeler: Cinsel İşlev Bozukluğu, Erkek Cinsel İşlev Bozuklukları, Kadın Cinsel İşlev Bozuklukları, Geleneksel Ve Tamamlayıcı Tedavi Uygulamaları, Kanıta Dayalı Uygulamalar 


\title{
Evidence-Based Traditional and Complementary Treatment Practices in Sexual Dysfunction
}

\begin{abstract}
World Health Organization defines sexual health as "not only disease, dysfunction or disability but also physical, emotional, mental and social sexual well-being". Sexual dysfunctions are among the factors affecting sexual health, which has an important role in the general health and well-being of individuals, couples and families. Premature ejaculation, erectile dysfunction in men; women have sexual dysfunction such as orgasm disorder, sexual interest/arousal disorder. Sexual dysfunction negatively affects couples' relationship quality, and can cause anxiety and depression in both men and women. Nowadays, in the treatment of sexual dysfunctions, the frequency of use of traditional and complementary therapies as well as medical treatment is gradually increasing due to dissatisfaction with the medical doctor or western medicine, avoiding the side effects of medical drugs, preferring natural methods. The National Complementary and Integrative Health Center has distinguished these methods as natural products, mind and body practices, and other complementary health approaches that do not fully fit any of these groups. Many individuals in the world and Turkey is in the sexual dysfunction. Although traditional and complementary treatment practices are used in the treatment of sexual dysfunctions, the effectiveness of very few has been shown in studies with high level of evidence. In this review, the evidence on traditional and complementary therapies used in sexual dysfunction in men and women was examined.
\end{abstract}

Key words: Sexual Dysfunction, Male Sexual Dysfunctions, Female Sexual Dysfunctions, Traditional And Complementary Treatment Practices, Evidence-Based Practices

\section{GİRIŞ}

Dünya Sağlık Örgütü (DSÖ) cinsel sağlığı: "Sadece hastalığın, işlev bozukluğunun veya sakatlığın olmaması değil; cinsellikle ilgili fiziksel, duygusal, zihinsel ve sosyal yönden iyilik halinin de sürdürülmesi” olarak tanımlamaktadır (WHO, 2010). Cinsel sağlık; bireylerin, çiftlerin ve ailelerin genel sağlığ 1 ve refahı ile toplulukların ve ülkelerin sosyal ve ekonomik gelişimi için temeldir. Cinsel sağlığı etkileyen önemli faktörler arasında cinsel işlev bozukluğu (CİB) yer almaktadır (WHO, 2020). CIB, Mental Bozuklukların Tanisal ve İstatistiksel El Kitabının (Diagnostic and Statistical Manual of Mental Disorders) beşinci baskısına (DSM-5) göre sınıflandırılmıştır (Tablo 1). CİB, çiftlerin ilişki kalitesini olumsuz etkilemekte hem kadın hem de erkekte anksiyete ve depresyona neden olabilmektedir (Günzler ve ark., 2010).

Tablo 1. DSM-5'e göre CİB:

\begin{tabular}{|c|c|}
\hline Kadında cinsel işlev bozuklukları & Erkekte cinsel işlev bozuklukları \\
\hline $\begin{array}{l}\text { - Kadında orgazm bozukluğu } \\
\text { - Kadında cinsel ilgi/uyarılma bozukluğu } \\
\text { - Cinsel organlarda-pelviste ağr1/ } \\
\text { - } \text { penetrasyon bozukluğu } \\
\text { - Taddenin/ilacın yol açtığı CiB } \\
\text { - Tanımlanmış diğer bir CïB } \\
\text { Tanmamış CIB }\end{array}$ & $\begin{array}{l}\text { - Geç boşalma } \\
\text { - Sertleşme bozukluğu } \\
\text { - Erkekte düşük cinsel istek bozukluğu } \\
\text { - } \text { Madken boşalma } \\
\text { - Tanıminlianmış diğ yol açtı̆̆ bir CİB CIBB } \\
\text { - Tanımlanmamış CİB }\end{array}$ \\
\hline
\end{tabular}

Dördüncü Uluslararası Cinsel Tıp Konsültasyonu'nda (2015); en az bir belirgin CİB bildiren kadınların prevalansının yaklaşık \%40 ile \%50 arasında olduğu, en sık görülen CİB'nin; isteksizlik ve uyarılma disfonksiyonu olmakla birlikte kadınların büyük bir kısmının birden fazla sayıda CİB'yi yaşadığı bildirilmiştir. Erkekler için ise; erken boşalma ve erektil 
Journal of Integrative and Anatolian Medicine

Bütünleyici ve Anadolu Tıbbı Dergisi
Cilt/ Volume: 2 Sayı / Issue: 3 Yll/Year: 2021
Yayıncı / Publisher

Sağlk Bilimleri Üniversitesi University of Health Sciences disfonksiyon en yaygın CİB'dir. Kadınlara göre erkeklerde CIBB'de daha az komorbidite vardır (McCabe ve ark., 2016). Yapilan bir sistematik derlemede Asyalı ve Avrupalı erkeklerde prevelans oranları sirasiyla; erektil disfonksiyonda \%0-95 karş1 \%1-89, erken boşalma \%0-49'a karş1 \%3-52, cinsellikten düşük memnuniyet \%3-38'e karş1 \%4-28, hipoaktif cinsel istek bozukluğu \%1-81'e karşı \%0-66, anorgazmi \%0.4'e karş1 \%3-\%65 olarak saptanmıştır (Irfan ve ark., 2020). Wolpe ve ark.'nın (2017) Brezilya'daki kadınlarda CIB sıklığını incelediği sistematik derlemede; Cİ'nin $\% 13$ ile $\% 79$, hipoaktif cinsel istek durumun $\% 11$ ile $\% 75$, cinsel uyarılma bozukluğunun $\% 8$ ile $\% 68$, orgazmik bozukluğun $\% 18$ ile $\% 55$, cinsel ağrı bozukluğunun $\% 1$ ile $\% 56$, vajinal kuruluğun \%29 ile \%41 arasında görüldüğü bildirilmiştir. Ramezani ve ark.'nın (2015) İran'da yaşayan tüm bireylerde CİB'nin epidemiyolojisinin incelendiği sistematik derleme ve meta-analizde; erektil disfonksiyon oran $1 \% 56$, kadın hipoaktif cinsel istek bozukluğu $\% 35$, kadın cinsel uyarılma bozukluğu \%34, kadın orgazmik bozukluğu \%35 ve kadın cinsel ağr1 bozukluğu \%20 olarak belirlenmiștir. Ülkemizde de CİB yaygın olarak görülmektedir. Türkiye'de yapılan çalışmalarda; kadınlardaki CİB prevalansının \%46-69 arasında değiştiği bildirilmiştir (Ege ve ark., 2010; Erbil, 2011; Gölbaşı ve ark., 2014). Cinsel Eğitim Tedavi ve Araştırma Derneği'nin (CETAD) 2007 yılında 1537 kişinin katılımı ile gerçekleştirdiği araştırmada; cinsel sorunu bulunanların sıklığ 1 $\% 23$, cinsel sorunu bulunmayanların sıklığ $\% 53$; cinsel birleşme ile ilgili sorun yaşayanların sıklığ $\% 9$, cinsel isteksizlik ve eşle uyum sorunları yaşayanların sıklığı \%10 olarak bulunmuştur. Ülkemizde erektil disfonksiyon siklığ $\% 33$ olarak bulunmuştur (Çayan ve ark., 2017). Türkiye'de yapılan bir çalışmada primipar kadınların \%20'sinin disparoni sorunu yaşadığ belirlenmiştir (Türk ve Çılgıın, 2020). Konya'da yapılan bir çalışmada ise erkeklerde erektil disfonksiyon yaygınlığı \%15, erken boşalma yaygınlığı \%29; kadınlarda vajinismus yaygınlığı
\%15, anorgazmi yaygınlığı \%5 olarak saptanmıştır (Y1lmaz ve Kucur, 2007).

Günümüzde, CİB tedavisinde, medikal tedavinin yanı sira geleneksel ve tamamlayıcı tedavi (GETAT) uygulamalarının kullanım sıklığı da giderek artmaktadır (Bülbül, 2017; Cooper ve ark., 2017). GETAT yöntemlerinin kullanım sıklığının artmasının en önemli nedenleri arasında; tıp hekiminden veya batı tıbbından memnun olmama, tıbbi ilaçların yan etkilerinden kaçınma, doğal yöntemleri tercih etme ve GETAT uygulayıcısı ile daha iyi bir ilişkiye sahip olma gibi nedenler yer almaktadır (Eardley ve ark., 2012). Türkiye'de cinsel sağlık/üreme sağlığı konusunda tedavi görmüş/ilaç kullanmış kişilerin oranı \%8 olarak belirtilmiştir. Cinsel organlarla ilgili bir sorun oluştuğunda ilk olarak yapılacak şey/danışılacak kişi sorulduğunda tıp dışı uygulama olduğunu belirten kadınların oran $1 \% 6$; erkeklerin ise \%3'tür (CETAD 2007). İstanbul'da, bitkisel ürünlerin satışının yapıldığ 1 bir çarşıda, bitkisel ürün almaya gelen 190 kişi ile yapılan bir çalışmada, bireylerin \%60'ının CİB nedeniyle bitkisel tedavi kullandıkları belirlenmiștir (Özçelik ve Toprak, 2015). Türkiye genelinde, son bir y1l içerisinde erektil disfonksiyon ürünü kullanan 410 erkeğin katılımıyla gerçekleştirilen bir çalışmada; erkeklerin cinsel performansı artırma veya erektil sorunların çözümü amacıyla \%13'ünün sadece bitkisel ürünler kullanmayı tercih ettiği; bitkisel ürünlerden orta ve yüksek derecede memnun olma oranının \%63 olduğu bildirilmiştir (Türkan ve ark., 2016).

CIB'nin tedavisinde GETAT uygulamalarının kullanılması, hemşirelerin bu alanda bilgi sahibi olmasını gerekli kılmaktadır. Çünkü hemşireler, bütüncül tıp felsefesi doğrultusunda bakım verirken cinsel sağlık alanını da ele almaktadır. Cinsel sağlık kapsamında ise hastalara CIBB'ye yönelik eğitim verilmekte ve danışanların yönlendirilmesi sağlanmaktadır (Fışkın ve Beji, 2014). Bu nedenle hemşireler CİB'de kullanılan kanıt düzeyi yüksek GETAT uygulamaları hakkında bilgi sahibi olmalı ve bu doğrultuda bakım vermelidir. 
Literatürde var olan konuyla ilgili bilimsel kanitların incelenmesinin, hastaların GETAT kullanımı konusunda doğru yönlendirilmelerine olanak sağlayacağı düşünülmektedir. $\mathrm{Bu}$ gerekçeden yola çıkarak derlememiz, kadın ve erkekte görülen CİB'de kullanılan GETAT uygulamaları ile ilgili çalışmaların kanıt düzeylerini incelemek ve literatüre katk1 sağlamak amacıyla hazırlanmıştır. Bu derlemede sunulan çalışmaların kanıt düzeyleri Joanna Briggs Enstitüsü tarafindan kabul edilen sınıflandırmaya göre değerlendirilmiştir (Tablo 2).

Tablo 2. Hemşirelikte kanıt düzeyi sınıflamaları Joanna Briggs Enstitüsü kanıt düzeyi sınıflaması (Joanna Briggs, 2003; Kocaman, 2003):

\begin{tabular}{|l|l|}
\hline Düzey & Kanıt tipi \\
\hline 1 & $\begin{array}{l}\text { Randomize Kontrollü Çalışmalarla (RKÇ) yapılmış sistematik incelemelerden elde edilen kanıtlar } \\
\text { En az bir, iyi tasarlanmış, RKÇ'den elde edilen kanıt }\end{array}$ \\
3.1 & $\begin{array}{l}\text { Randomize olmayan iyi tasarlanmış kontrollü çalışmalardan elde edilen kanıt } \\
3.2\end{array}$ \\
3.3 & $\begin{array}{l}\text { Birden fazla merkez/grup tarafından yapılmış, iyi tasarlanmış kohort ya da vaka-kontrol } \\
\text { çalışarından elde edilen kanıt } \\
\text { çalışmaların etkileyici sonuçları }\end{array}$ \\
4 & $\begin{array}{l}\text { Klinik deneyimlere dayalı, saygın otoritelerin görüşleri, tanımlayıcı çalışmalar ya da uzman komite } \\
\text { raporları. }\end{array}$ \\
\hline
\end{tabular}

\section{Geleneksel ve Tamamlayıcı Tedavi Uygulamaları}

DSÖ tarafından geleneksel tıp: "Açıklanabilir olsun ya da olmasın, sağlığın korunmasında ve ayrıca fiziksel ve zihinsel hastalığın önlenmesinde, tanısında, iyileştirilmesinde veya tedavisinde kullanılan farklı kültürlere özgü teorilere, inançlara ve deneyimlere dayanan bilgi, beceri ve uygulamaların tamamı" olarak ifade edilmektedir. Tamamlayıcı tıp veya alternatif tıp ise: "Ülkenin kendi geleneğinin veya konvansiyonel tıbbının bir parçası olmayan ve sağlık sistemine tam olarak entegre edilmemiş çok çeşitli sağlık hizmetleri uygulamaları" olarak tanımlanmaktadır (WHO, 2020). Tibbın alternatifinin olmayacağı eleştirileri üzerine alternatif sözcüğü yerine, "geleneksel ve tamamlayıcı" ifadesi kullanılmaya başlanmıştır (Tütücü, 2017: 14). Ülkemizde yayınlanan 27 Ekim 2014 tarihli "Geleneksel ve Tamamlayıc1 Tıp Uygulamaları Yönetmeliği'nde” akupunktur, apiterapi, fitoterapi, hipnoz, sülük uygulaması, homeopati, kayropraktik, kupa uygulaması, larva uygulamas1, mezoterapi, proloterapi, osteopati, ozon uygulaması, refleksoloji ve müzikterapi GETAT uygulamalarına yer verilmiştir (Resmi Gazete, 2014). Ulusal Tamamlayıc1 ve İntegratif Sağlik Merkezi (National Center for Complementary and Integrative Health) ise bu yöntemleri doğal ürünler ile zihin ve beden uygulamaları olarak ayırmıştır. Ayrıca bu grupların hiçbirine tam olarak uymayan yaklaşımları diğer tamamlayıcı sağlık yaklaşımları olarak belirtmiştir (NCCIH, 2020).

\section{Cinsel İşlev Bozukluklarında Kullanılan GETAT Uygulamaları}

Günümüzde CİB'de sıklıkla kullanılan GETAT uygulamaları aşağıda sunulmuştur.

\subsection{Doğal Ürünler}

Doğal ürünler; bitkiler, vitaminler, mineraller ve probiyotikler gibi çeşitli ürünleri içermektedir. Bazı doğal ürünlerin yararlı etkilerine dair kanitlar mevcut olsa da, bu ürünlerin insan vücudundaki etkileri, ilaçlarla ve diğer doğal ürünlerle potansiyel etkileşimleri hakkında daha fazla araştırmaya ihtiyaç 
Journal of Integrative and Anatolian

Medicine

Bütünleyici ve Anadolu Tıbbı Dergisi
Cilt/ Volume: 2 Sayı / Issue: 3

Yll/Year: 2021
Yayncs / Publisher

Sağllk Bilimleri Üniversitesi

University of Health Sciences duyulmaktadır (NCCIH, 2020). Doğal ürünlerin CİB'de kullanımına yönelik araştırmalara bu bölümde yer verilmiştir.

Dording ve ark.'nın (2015) yaptığı çift kör plasebo RKÇ'de; postmenopozal dönemdeki kadınlarda antidepresan kaynaklı CIBB tedavisinde, 12 hafta boyunca kullanılan Maka kökünün (Latince adı. Lepidium meyenii, maca) orgazm olmayı kolaylaştırdığı ve CIBB tedavisinde etkili olabileceği belirtilmiştir (Kanıt düzeyi 2: KD2). Chung ve ark.'nın (2015) plasebo, çift kör, çapraz RKÇ'sinde kore kırmızı ginsenginin oral kullanımının premenopozal dönemdeki kadınlarda kontrol grubuna göre cinsel işlevi iyileştirdiği, ancak plasebo grubu ile karşılaştırıldığında anlamlı bir fark bulunmadığ1 belirlenmiștir (KD2). Postigo ve ark.'nın (2016) yürüttüğü prospektif, randomize, çift kör, plasebo kontrollü bir klinik çalışmada; 90 günlük demir dikeni (Tribulus terrestris, çarık dikeni) kullanımının menopoz dönemindeki kadınların cinsel sorunlarının tedavisinde etkili olduğu belirtilmiştir (KD2). İran'da yürütülen bir RKÇ'da; CİB'e sahip postmenopozal kadınlarda dört hafta boyunca günde iki kez $500 \mathrm{mg}$ Panax ginseng uygulamasının etkisi incelenmiştir. 4 hafta uygulanan Panax ginseng'inin cinsel işlevi iyileştirmede ve menopoz semptomlarını hafifletmede plasebo grubuna göre istatistiksel olarak anlamlı etkiye sahip olduğu bulunmuştur (KD2) (Ghorbani ve ark., 2019). Najafi ve Ghazanfarpour'un (2018) fitoöstrojenlerin menopozdaki kadınların CİB'nin üzerindeki etkinliğinin incelendiği sistematik derleme ve meta-analizde; çam kabuğu ekstresi (Piknogenol), çemen bitkisi (Trigonella foenumgraecum) ve rezenenin (Foeniculum vulgare) CIBB'yi iyileştirmede kullanılabileceği; ancak kırmızı yonca (Trifolium pratense, çayır gülü, çayır dutu), genistein (fitoöstrojen olarak tanımlanan bir izoflavon), keten tohumu (Linum usitatissimum) ve soyanın (Glycine max) CIBB'yi iyileștirmede umut verici bir etkiye sahip olmadığ 1 belirtilmiştir (KD1). Molkara ve ark.'nın (2018) yürüttüğü RKÇ'de; CİB'ye sahip olan kadınlar; yabani havuç (Daucus carota) kullanacak grup $(n=32)$, cinsel sağlık eğitimi verilecek grup $(n=32)$ ve hem yabani havuç kullanan aynı zamanda cinsel sağlık eğitimi verilen grup $(n=32)$ olmak üzere randomize olarak 3 gruba atanmıştır. Bütün gruplarda 8 haftalık müdahale sonrasinda vajinal kayganlaşma, orgazm ve disparoni açısından anlamlı fark belirlenmiştir. Tek bașına cinsel sağlık eğitimine kıyasla yabani havuç kullandırılan ve aynı zamanda cinsel sağlık eğitimi verilen kadınların CİB'lerinin anlamlı düzeyde iyileştiği belirlenmiştir (KD2).

Ernst ve ark.'nın (2011) yaşlı erkek ve kadınlarda CİB tedavisinde GETAT kullanımına yönelik 4 sistematik derleme değerlendirilmiş; erektil disfonksiyon tedavisinde yohimbin ve ginsengin olumlu etkileri olduğu; erektil disfonksiyon ve cinsel disfonksiyon tedavisinde akupunktur ve maka bitkisi kullanımına yönelik kanitların yetersiz olduğu belirtilmiştir (KD1). Shah ve ark.'nın (2012) yaptığ 1 plasebo, çift kör, RKÇ'de; erektil disfonksiyon tedavisinde çoklu bitki takviyesinin (VigRX Plus) cinsel işlevi iyileştirmede plasebodan daha etkili olduğu ve hafif şiddette ateş gibi yan etkilerinin plasebo grubu ile benzer olduğu belirtilmiştir (KD2). Erektil disfonksiyon tedavisinin incelendiği 5 sistematik derlemenin değerlendirildiği çalışmada; yohimbin, safran (Crocus sativus) ve ginseng kullanımının olumlu sonuçları olduğu bildirilmiş, fakat akupunkturun erektil disfonksiyon tedavisinde kullanımına ilişkin yeterli kanıt olmadığı belirtilmiştir (KD1) (Irani ve ark., 2018). Borrelli ve ark.'nın (2018) yaptığ1 sistematik derleme ve meta-analizde; Ginseng ve Prelox'un (piknogenol ve L-arginin aspartat kombinasyonu) erektil disfonksiyonu önemli ölçüde iyileştirdiği; sahil çamı (Pinus pinaster) ve macanın ise olumlu etkileyebileceği bildirilmiştir. Ancak safran ve demir dikeninin erektil disfonksiyonu iyileştirmesine yönelik karışık sonuçlar verdiği belirtilmiştir (KD1). Türk Üroloji Derneği'nin hazırladığ 1 kitapçıkta uzun yillar afrodizyak etkisi nedeni ile kullanılan demir dikeninin, psikojenik ya da hafif-orta erektil disfonksiyon sorunu yaşayan hastalarda kullanımı önerilmektedir (KD4). Shin ve ark.'nın (2010) sistematik derlemesinde; makanın 
erkeklerde erektil disfonksiyon ve cinsel istek; kadınlarda CİB'lerin tedavisindeki etkinliği için sınırlı kanıt olduğu, maka kullanımının riskleri hakkındaki mevcut bilgilerin yetersiz olduğu bildirilmiştir (KD1). Thu ve ark.'nın (2017) 11 çalışmayı incelediği sistematik derlemede; tongkat ali bitkisinin (Eurycoma longifolia jack) erkeklerin libidosunu ve genel cinsel performansını artırmada etkili olabileceği belirtilmiştir (KD1). Kamenov ve ark.'nın (2017) Bulgaristan'daki 10 hastanede yürüttüğü, çift kör, plasebo kontrollü bir RKÇ'de; 12 hafta boyunca oral uygulanan demir dikeninin hafif ve orta derecede erektil disfonksiyonu ve erkeklerde düşük libidoyu iyileştirdiği ve tedavide yararlanılabileceği belirtilmiştir (KD2).

\subsection{Zihin ve Beden Uygulamaları}

Zihin ve beden uygulamaları, eğitimli bir uygulayıcı tarafından yönetilen veya öğretilen çeşitli prosedür veya teknikleri içermektedir. Zihin ve beden uygulamaları arasında yoga, kayropraktik, osteopatik manipülasyon, meditasyon, akupunktur, gevşeme teknikleri (nefes egzersizleri, rehberli görüntüler ve ilerleyici kas gevşemesi), tai chi, hipnoterapi ve pilates gibi yöntemler yer almaktadır $(\mathrm{NCCIH}$, 2020). Zihin ve beden uygulamalarının CİB'deki kullanımına yönelik araştırmalara bu bölümde yer verilmiştir.

Dhikav ve ark.'nın (2010) yürüttüğü çalışmada; 12 hafta yoga uygulayan kadınların arzu, uyarılma, vajinal kayganlık, orgazm, memnuniyet ve disparoni cinsel ișlevlerinde anlamlı derecede iyileşme olduğu bildirilmiştir. Yoganın kadınlarda cinsel işlevlerin tüm alanlarını iyileştirmede etkili bir yöntem olduğu belirtilmiştir (KD3.3). Benzer şekilde Kim ve ark.'nın (2013) yaptığı RKÇ'da; 12 hafta yoga uygulamanın metabolik sendromlu kadınlarda cinsel uyarılma ve vajinal kayganlaşmada önemli iyileşme sağladığ 1 bildirilmiştir (KD2). Najafidoulatabad ve ark.'nın (2014) multipl skleroz hastası İranlı kadınların katılımıyla yürüttüğü RKÇ'da; 3 ay uygulanan yoga egzersizlerinin cinsel memnuniyeti anlamlı olarak artırdığı bildirilmiştir (KD2). Durna ve ark.'nın (2020) yaptığı sistematik derlemede hem bireysel hem de grup odaklı bilinçli farkındalık temelli müdahalelerin (mindfulness temelli müdahale), kadınlarda CİB'de anlamlı düzeyde iyileşme sağladığı ve bu iyileşmelerin uzun dönemde korunduğu belirtilmiştir (KD1). Yapılan bir çalışmada 3 hafta uygulanan akupunkturun kadınların CIB ile ilgili semptomlarını anlamlı düzeyde azalttığı belirtilmiştir (KD3.2) (Running ve ark., 2012). Oakley ve ark.'nın (2016) hipoaktif cinsel istek bozukluğu olan premenopozal kadınların katılımıyla yürüttüğü çalışmada; 5 hafta boyunca haftada iki kez 25 dakikalık akupunktur uygulanan kadınların özellikle cinsel istek, uyarılma, vajinal kayganlaşma ve orgazm alanında önemli iyileşmeler sağladığı bildirilmiştir (KD3.2). Khamba ve ark.'nın (2013) antidepresanların kullanımına sekonder CİB bulunan hastaların katılımıyla yürüttüğü çalışmada; akupunkturun, kadınlarda libidoyu arttırmada ve vajinal kayganlaşmayı iyileştirmede önemli etkisi bulunduğu belirtilmiștir. Erkek katılımcilarda ise cinsel işlevi iyileştirdiği bildirilmiş (KD3.3). CİB'de yararlanılan bir diğer uygulama ise hipnozdur. Postmenopoz dönemindeki kadınların katılımıyla yapılan bir çalışmada; 5 haftalık hipnotik gevşeme terapisi uygulanan kadınlarda, cinsel zevk ve cinsel rahatsızlık alanlarında önemli iyileşme olduğu bildirilmiştir (KD2) (Johnson ve ark., 2016). Kumalasari ve ark.'nın (2020) yaptığ 1 meta-analizde; hipnozun cinsel ilişki sırasındaki ağrıyı azaltabileceği bildirilmiştir (KD1). Elkins ve ark.'nın (2014) yaptığı bir vaka çalışmasında; kalıcı genital uyarılma bozukluğu olan 71 yaşındaki bir kadında 9 seanslık hipnoterapi sonucunda olumlu gelişme olduğu belirtilmiştir (KD3.3).

Lee ve ark.'nın (2009) sistematik derlemesinde; akupunkturun erektil disfonksiyon tedavisinde kullanımının etkisiz bir müdahale olduğu bildirilmiştir. Erektil disfonksiyon tedavisinde akupunkturun etkisine yönelik daha fazla çalışmaya ihtiyaç duyulduğu belirtilmiştir (KD1). Sunay ve ark.'nın (2011) erken boşalma sorunu olan erkeklerin katılımıyla yürüttüğü 
plasebo kontrollü RKÇ'de; akupunkturun paroksetin ilacindan daha az etkili olmasına rağmen, plaseboya kıyasla boşalmayı daha fazla geciktirdiği bildirilmiştir (KD2). Tsai ve ark.'nın (2014) 7 RKÇ’yi incelediği sistematik derlemede; akupunkturun erektil disfonksiyon ve erken boşalma sorununda ilaç tedavisi veya hipnoterapi ile benzer olumlu etkisi bulunduğu; ancak daha fazla çalışmaya ihtiyaç olduğu belirtilmiştir (KD1). Cui ve ark.'nın (2016) sistematik derlemesinde; akupunkturun tek başına erektil disfonksiyonu iyileştirdiğini destekleyen mevcut kanıtların yetersiz olduğu ve mevcut çalışmaların akupunkturun spesifik iyileştirici etkisini gösteremediği belirtilmiştir (KD1). Şahin ve ark.'nın (2016) erken boşalma tedavisinde akupunkturun, dapoksetin ilacindan daha az etkili olmasına rağmen, önemli bir boşalma geciktirici etkisi olduğunu bildirmiştir (KD2). Ciocanel ve ark.'nın (2019) incelediği sistematik derlemelerde; akupunktur, kırmızı ginseng, yohimbin ve Çin bitkileri gibi alternatif tedavilerin erektil disfonksiyon tedavisinde kullanımının çelişkili sonuçları olduğu belirtilmiştir. Aynı çalışmada yohimbin, kırmızı ginseng ve Çin bitkilerinin olumlu bir etkiye sahip olduğu gösterilmiş olsa da, daha iyi çalışmalara ihtiyaç olduğu belirtilmiştir (KD1). Dhikav ve ark.'nın (2007) yaptığı çalışmada; erken boşalma sorunu olan hastalarda yoganın anlamlı düzeyde iyileşme sağladığı, ancak daha büyük örneklem içeren daha fazla çalışmaya ihtiyaç olduğu belirtilmiştir (KD3.3). Mamidi ve Gupta'nın (2013) yürüttüğü çalışmada; erken boşalma sorunu olan hastalar, yoga grubu ve doğal gruba (alt karın ve alt ekstremite masajı, ardından buhar ve oturma banyosu, alt karın bölgesine çamur paketi ve akupresür uygulaması) randomize edilmiştir. Uygulama sonrası yoga ve doğal uygulamanın erken boşalmayı iyileştirmediği bildirilmiştir (KD2). Yeni bir uygulama olarak ise erken boşalmayı önlemede Transkutanöz Elektriksel Nöromüsküler Stimülasyon (TENS) uygulaması önerilmiştir. Gerekçe olarak boşalmada işlevi olan bulbospongiosus kasının kasılmasının geçici inhibisyonunu sağlayacağı gösterilmiştir
(Gruenwald ve ark., 2017). Yapılan bir çalışmada 20 hastadan 17'sinde plasebo tedaviye kiyasla TENS uygulamasının mastürbasyon esnasındaki boşalma gecikme sürelerini ortalama 3.5 kat arttırdığı bildirilmiştir (KD3.3) (Shechter ve ark., 2020).

\subsection{Diğer Yaklaşımlar}

Doğal ürünler ve zihin ve beden uygulamalarının hiçbirine tam olarak uymayan yaklaşımlar "diğer yaklaşımlar" olarak ele alınmaktadır. Ayurveda tıbbı, geleneksel Çin tıbbı, homeopati ve naturopati gibi yaklaşımlar diğer tamamlayıcı sağlık yaklaşımları olarak belirtilmektedir (NCCIH, 2020).

Cooper ve ark.'nın (2017) sistematik derlemesinde; akupunktur, Ayurveda tıbb1 ve "severance secret" kreminin sinırlı verilere dayanarak plaseboya göre vajina içine boşalma süresini iyileştirdiği; Çin bitkisel ilaçlarının seçici serotonin geri alım inhibitörleri kadar etkili olmadığı belirtilmiştir. Bu çalışmada bahsedilen tüm uygulamalar için daha iyi yapılmış RKÇ 'a ihtiyaç olduğu bildirilmiştir (KD1).

\section{SONUÇ}

Derlememizde, CİB'de kadınlara yönelik doğal ürünlerden maka kökü, kore kırmızı ginsengi, demir dikeni, Panax ginseng, çam kabuğu ekstresi, çemen bitkisi ve rezene, kırmızı yonca, genistein, keten tohumu, soya, yabani havuca; zihin ve beden uygulamalarından yoga, bilinçli farkındalık temelli müdahaleleri, akupunktur, hipnoza yer verilmiştir. Erkeklere yönelik ise doğal ürünlerden yohimbin, ginseng, maka bitkisi, çoklu bitki takviyesi, safran, sahil çamı, demir dikeni, tongkat ali bitkisi, demir dikeni; zihin ve beden uygulamalarından yoga, akupunktur, TENS'ye; diğer yaklaşımlardan Ayurveda tıbbı ve Çin tıbbına yer verilmiştir. Ulusal yönetmeliğimizde yer alan GETAT uygulamaları arasında yer alan akupunktur, fitoterapi ve hipnozun CİB'ye yönelik yapılan çalışmalarda daha fazla yer verildiği belirlenmiştir.

Sonuç olarak kadınlara CİB'e yönelik maka kökü, demir dikeni, Panax ginseng, çam kabuğu 
ekstresi, çemen bitkisi, rezene, yoga, bilinçli farkındalık temelli müdahale (mindfulness temelli müdahale), akupunktur ve hipnozun; vajinal kayganlaşma, orgazm, ağrıya yönelik yabani havucun olumlu etkilerinin olduğuna yönelik kanıt düzeyi yüksek çalışmalara rastlandi. Erkeklerde ise erektil disfonksiyona yönelik yohimbin, ginseng, çoklu bitki takviyesi, Prelox, demir dikeninin ve Çin bitkilerinin; genel cinsel performansı artırmaya yönelik tongkat ali bitkisinin; erektil disfonksiyon ve erken boşalmaya yönelik akupunkturun olumlu etkilerinin olduğuna yönelik kanıt düzeyi yüksek çalışmalara yer verildiği görülmüştür. Fakat Cỉ'de geleneksel ve tamamlayıcı tedavi uygulamalarına yönelik daha fazla kanıt temelli çalışmaya ihtiyaç duyulması nedeniyle hemşireler ve akademisyen hemşireler bu alanda daha fazla araştırmalar yapmalıdır. Ayrıca hemşireler, CİB'ye yönelik danışmanlık verirken GETAT uygulamalarının medikal tedavi yerine geçmediği ve GETAT uygulamalarından bitkisel tedaviler başta olmak üzere birçoğunun etkinlik, yan etkiler ve uzun dönemde etkileri açısından daha fazla araştırılması gerektiği bilgisini hasta veya danışanlarına vermelidir.

\section{KAYNAKLAR}

Amerikan Psikiyatri Birliği (2014). Beşinci Baskı (DSM5), Tanı Ölçütleri Başvuru Elkitabı. (Çev. E. Köroğlu). Hekimler Yayın Birliği, Ankara. (Eserin orijinali 2013'te yayımland1). 205-217.

Borrelli, F., Colalto, C., Delfino, D.V., Marcello, I., Angelo A.I. (2018). Herbal Dietary Supplements for Erectile Dysfunction: A Systematic Review and Meta-Analysis. Drugs 78, 643-673.

Bülbül, T. (2017). Cinsel İşlev Bozukluklarında İntegratif Tıp Uygulamaları. Sağlık Bilimleri Dergisi, 26(3), 282-286.

Çayan, S., Kendirci, M., Yaman, Ö., Aşçı, R., Orhan, İ., Usta, M. F., Ekmekçioğlu, O., \& Kadıoğlu, A. (2017). Prevalence of erectile dysfunction in men over 40 years of age in Turkey: Results from the Turkish society of andrology male sexual health study group. Turkish Journal Urology 43(2), 122129.
Chung, H. S., Hwang, I., Oh, K. J., Lee, M. N., \& Park, K. (2015). The effect of Korean Red Ginseng on sexual function in premenopausal women: placebo-controlled, double-blind, cross over clinical trial. Evidence-Based Complementary and Alternative Medicine. 913158.

Cinsel Eğitim ve Araştırma Derneği-CETAD (2007). Cinsel Yaşam ve Sorunları. CETAD yayını. S:6377.

Ciocanel, O., Power, K., \& Eriksen, A. (2019). Interventions to treat erectile dysfunction and premature ejaculation: An overview of systematic reviews. Sexual medicine, 7(3), 251-269.

Cooper, K., Martyn-St James, M., Kaltenthaler, E., Dickinson, K., Cantrell, A., Ren, S., ... \&Hood, C. (2017). Complementary and alternative medicine for management of prematüre ejaculation: a systematic review. Sexual medicine, 5(1), e1-e18.

Cui, X., Zhou, J., Qin, Z., \& Liu, Z. (2016). Acupuncture for erectile dysfunction: a systematic review. BioMed research international, https://doi.org/10.1155/2016/2171923

Dhikav, V., Karmarkar, G., Gupta, R., \&Verma, M. (2010). Yoga in Female Sexual Functions. JSex Med;7:964-970.

Dhikav, V., Karmarkar, G., Gupta, M., \& Anand, K. S. (2007). Ejaculatory Disorders: Yoga in Premature Ejaculation: A Comparative Trial with Fluoxetine. The Journal of Sexual Medicine, 4(6), 1726-1732.

Dording, C. M., Schettler, P. J., Dalton, E. D., Parkin, S. R., Walker, R. S., Fehling, K. B., ... \&Mischoulon, D. (2015). A double-blind placebo-controlled trial of maça root as treatment for antidepressant-induced sexual dysfunction in women. Evidence-Based Complementary and Alternative Medicine, 949036.1-9.

Durna, G., Ülbe, S., \& Dirik, G. (2020). Kadında Cinsel İşlev Bozukluğunun Tedavisinde Bilinçli Farkındalık Temelli Müdahaleler: Sistematik Bir Derleme. Psikiyatride Güncel Yaklaşımlar, 11(4), $1-1$.

Eardley, S., Bishop, F. L., Prescott, P., Cardini, F., Brinkhaus, B., Santos-Rey, K., ... \& Uehleke, B. (2012). A systematic literaturere view of complementary and alternative medicine prevalence in EU. Complementary Medicine Research, 19 (2), 18-28. 
Journal of Integrative and Anatolian Medicine

Bütünleyici ve Anadolu Tıbbı Dergisi
Cilt/ Volume: 2 Sayı / Issue: 3 Yil/Year: 2021
Yayıncı / Publisher

Sağllk Bilimleri Üniversitesi University of Health Sciences
Ege, E., Akın, B., Arslan, S. Y., \& Bilgili, N. (2010). Sağlıklı kadınlarda cinsel işlev bozukluğu sıklığı ve risk faktörleri. $T \ddot{U} B A V$ Bilim Dergisi, 3(1), 137-144.

Elkins, G. R., Ramsey, D., \& Yu, Y. (2014). Hypnotherapy for persistent genital arousal disorder: a case study. International Journal of Clinical and Experimental Hypnosis, 62(2), 215-223.

Erbil, N. (2011). Prevalence and risk factors for female sexual dysfunction among Turkish women attending a maternity and gynecology out patient clinic. Sexuality and Disability, 29(4), 377-386.

Ernst, E., Posadzki, P., \& Lee, M. S. (2011). Complementary and alternative medicine (CAM) for sexual dysfunction and erectile dysfunction in older men and women: an overview of systematic reviews. Maturitas, 70(1), 37-41.

Fışkın, G., \& NK, B. (2014). Cinsel işlevin değerlendirilmesi ve hemşirenin rolü. Androloji Bülteni, 56, 73-76.

Ghorbani, Z., Mirghafourvand, M., Charandabi, S. M. A., \& Javadzadeh, Y. (2019). The effect of ginseng on sexual dysfunction in menopausal women: A double-blind, randomized, controlledtrial. Complementary therapies in medicine, 45, 57-64.

Gölbaşı, Z., Tuğut, N., Erenel, A., \& Eroğlu, K. (2014). Jinekoloji polikliniğine başvuran evli kadınlarda cinsel işlev bozukluğu yaygınlığı ve ilişkili bazı faktörler. Cumhuriyet Medical Journal, 36(1), 110.

Gruenwald, I., Serefoglu, E. C., Gollan, T., Springer, S., Meiry, G., Appel, B., \& Shechter, A. (2017). Transcutaneous neuromuscular electrical stimulation may be beneficial in the treatment of premature ejaculation. Medical hypotheses, 109, 181-183.

Günzler, C., Kriston, L., Agyemang, A., Riemann, D., \& Berner, M. M. (2010). Sexuelle Funktionsstörungen bei Herzkranken und die Folgen. Herz, 35(6), 410-419.

Irani, M., Ghaffari Sardasht, F., Ghazanfarpour, M., Mansouri, E., Entezari, E., \&Khadivzadeh, T. (2018). A Systematic Overview of Reviews on the Efficacy of Complementary and Alternative Medicine in Erectile Dysfunction. Journal of Midwifery and Reproductive Health, 6(4), 14761485.
Irfan, M., Hussain, N. H. N., Noor, N. M., Mohamed, M., Sidi, H., \& Ismail, S. B. (2020). Epidemiology of male sexual dysfunction in Asian and European regions: a systematic review. American journal of men's health, 14(4), 1557988320937200.

Joanna Briggs Institue. [Internet]. www.joannabrggis.edu.au./about.html.

Johnson, A. K., Johnson, A. J., Barton, D., \& Elkins, G. (2016). Hypnotic relaxation therapy and sexual function in postmenopausalwomen: Results of a randomized clinical trial. International Journal of Clinical and Experimental Hypnosis, 64(2), 213224.

Kamenov, Z., Fileva, S., Kalinov, K., \& Jannini, E. A. (2017). Evaluation of the efficacy and safety of Tribulus terrestris in male sexual dysfunction-a prospective, randomized, double-blind, placebocontrolled clinical trial. Maturitas, 99, 20-26.

Khamba B, Aucoin M, Lytle M, et al: Efficacy of acupuncture treatment of sexual dysfunction secondary to antidepressants. $J$ Altern Complement Med 2013; 19:862-869 40.

Kim, H. N., Ryu, J., Kim, K. S., \& Song, S. W. (2013). Effects of yoga on sexual function in women with metabolic syndrome: a randomized controlled trial. The journal of sexual medicine, 10(11), 2741-2751.

Kocaman, G. (2003). Hemşirelikte Kanıta Dayalı Uygulama. Hemşirelikte Araştırma Geliştirme Dergisi, 5(2), 61-69.

Kumalasari, R. D., Tamtomo, D. G., \& Prasetya, H. (2020). Hypnosis and dyspareunia: a meta analysis. Indonesian Journal of Medicine, 5(4), 291-298.

Lee, M. S., Shin, B. C., \& Ernst, E. (2009). Acupuncture for treating erectile dysfunction: a systematic review. BJU international, 104(3), 366-370.

Mamidi, P., \& Gupta, K. (2013). Efficacy of certain yogic and naturopathic procedures in premature ejaculation: A pilot study. International journal of yoga, 6(2), 118.

McCabe, M. P., Sharlip, I. D., Lewis, R., Atalla, E., Balon, R., Fisher, A. D., ... \& Segraves, R. T. (2016). Incidence and prevalence of sexual dysfunction in women and men: a consensus statement from the Fourth International Consultation on Sexual 
Journal of Integrative and Anatolian Medicine

Bütünleyici ve Anadolu Tibbı Dergisi
Cilt/ Volume: 2 Sayı / Issue: 3

Yil/Year: 2021
Yayıncı / Publisher

Sağllk Bilimleri Üniversitesi University of Health Sciences
Medicine 2015. The journal of sexual medicine, 13(2), 144-152.

Molkara, T., Akhlaghi, F., Ramezani, M. A., Salari, R., Vakili, V., Kamalinejad, M., ... \&Motavasselian, M. (2018). Effects of a food product (based on Daucus carota) and education based on traditional Persian medicine on female sexual dysfunction: a randomized clinical trial. Electronic physician, $10(4), 6577$.

NajafNajafi, M., \& Ghazanfarpour, M. (2018). Effect of phytoestrogens on sexualfunction in menopausalwomen: a systematic review and meta-analysis. Climacteric, 21(5), 437-445.

Najafidoulatabad, S., Mohebbi, Z. \&Nooryan K. (2014). Yoga effects on physical activity and sexual satisfaction among Iranian women with multiple sclerosis: a randomized controlled trial. African Journal of Traditional, Complementary and Alternative Medicines, 11(5), 78-82.

National Center for Complementary and Integrative Health (Nccih).

https://www.nccih.nih.gov/health/complementary -alternative-or-integrative-health-whats-in-aname Erişim tarihi: 18.05.2020.

Oakley SH, Walther-Liu J, Crisp CC, et al: Acupuncture in premenopausal women with hypoactive sexual desire disorder: a prospective cohort pilot study. Sex Med 2016; 4: e176-e181.

Ortaç M, Kadığlu A, Tribulus Terrestis (TT)'in Erektil Disfonksiyon Tedavisinde Kullanımı, Türk Üroloji Derneği.s. 7.

Özçelik, G., \& Toprak, D. (2015). Bitkisel tedavi neden tercih ediliyor? Ankara Medical Journal, 15(2).

Postigo, S., Lima, S.M.R.R., Yamada, S.S., dos Reis, B.F., da Silva, G.M.D., \& Aoki, T. (2016). Assessment of the effects of Tribulus terrestris on sexual function of menopausal women. Revista Brasileira de Ginecologia e Obstetrícia/ RBGO Gynecology and Obstetrics, 38(03), 140-146.

Ramezani, M. A., Ahmadi, K., Ghaemmaghami, A., Marzabadi, E. A., \&Pardakhti, F. (2015). Epidemiologyof sexual dysfunction in Iran: A systematic review and meta-analysis. International journal of preventive medicine, 6 .
Resmî Gazete (2014). Geleneksel ve Tamamlayıcı Tıp Uygulamaları Yönetmeliği. Tarih: 27.10.2014; Say1: 29158.

Running, A., Smith-Gagen, J., Wellhoner, M., \& Mars, G. (2012). Acupuncture and female sexual dysfunction: a time-series study of symptom relief. Medical Acupuncture, 24(4), 249-255.

Sahin, S., Bicer, M., Yenice, M. G., Seker, K. G., Yavuzsan, A. H., \& Tugcu, V. (2016). A prospective randomized controlled study to compare acupuncture and dapoxetine for the treatment of premature ejaculation. Urologia internationalis, 97(1), 104-111.

Shechter, A., Serefoglu, E. C., Gollan, T., Springer, S., Meiry, G., Appel, B., \& Gruenwald, I. (2020). Transcutaneous functional electrical stimulation-a novel therapy for premature ejaculation: results of a proof of concept study. International journal of impotence research, 32(4), 440-445.

Shah, G. R., Chaudhari, M. V., Patankar, S. B., Pensalwar, S. V., Sabale, V. P., \& Sonawane, N. A. (2012). Evaluation of a multi-herb supplement for erectile dysfunction: a randomized double-blind, placebocontrolled study. BMC complementary and alternative medicine, 12(1), 155.

Shin, B. C., Lee, M. S., Yang, E. J., Lim, H. S., \& Ernst, E. (2010). Maca (L. meyenii) for improving sexual function: a systematic review. $B M C$ complementary and alternative medicine, 10(1), 44.

Sunay, D., Sunay, M., Aydoğmuş, Y., Bağbancı, Ş., Arslan, H., Karabulut, A., \& Emir, L. (2011). Acupuncture versus paroxetine for the treatment of premature ejaculation: a randomized, placebo-controlled clinical trial. European urology, 59(5), 765-771.

Thu, H. E., Mohamed, I. N., Hussain, Z., Jayusman, P. A., \& Shuid, A. N. (2017). Eurycoma Longifolia as a potential adoptogen of male sexual health: a systematic review on clinical studies. Chinese journal of natural medicines, 15(1), 71-80.

Tsai, M. Y., Liu, C. T., Chang, C. C., Chen, S. Y., \& Huang, S. T. (2014). Overview of the relevant literature on the possible role of acupuncture in treating male sexual dysfunction. Acupuncture in Medicine, 32(5), 406-410. 
Journal of Integrative and Anatolian Medicine

Bütünleyici ve Anadolu Tıbbı Dergisi
Cilt/Volume: 2 Sayı / Issue: 3 Yil/Year: 2021
Yayınc / Publisher Sağlk Bilimleri Üniversitesi University of Health Sciences
Turkan, S., Cayan, S., \& Kadioglu, A. (2016). Views of Turkish Men Regarding the use of Drugs and Products for Increasing Sexual Performance. Journal Of Clinical And Analytical Medicine, 7(5), 672-675.

Türk, R. ve Çılgın, H. (2020). Comparison of primipara women's pre-pregnancy, pregnancy, and postpartum sexual lives. Journal of Surgery and Medicine, 4(11), 1018-1022.

Tütücü, S. (2017). Tibbın Alternatifi Olmaz. Geleneksel ve Alternatif Tamamlayıc1 Tip Uygulamaları. Ankara: Türk Tabipler Birliği Yayınları.14.

Yilmaz, E. ve Kucur, R (2007). Konya il merkezinde yaşayan evli nüfusta cinsel sorunların araştırılması (Doctoral dissertation, Selçuk Üniversitesi Tip Fakültesi).
Wolpe, R.E., Zomkowski, K., Silva, F.P., Queiroz, A.P.A., \& Sperandio, F.F. (2017). Prevalence of female sexual dysfunction in Brazil: A systematic review. European Journal of Obstetrics \& Gynecology and Reproductive Biology, 211, 26-32.

World Health Organization. Developing sexual health programmes. WHO/RHR/HRP/10.22, 2010. (cited 17.05.2020).

World Health Organization. Sexual health [Internet]. [cited 16.05.2020] Available from: https://www.who.int/health-topics/sexualhealth\#tab=tab_1.

World Health Organization. [Internet]. [cited 17.05.2020] Available from https://www.who.int/healthtopics/traditional-complementary-andintegrative-medicine $\#$ tab $=$ tab_1. 